\title{
SINGLE-LINED SPECTROSCIC APPEARANCES DURING THE EVOLUTION OF A MASSIVE BINARY SYSTEM.
}

\author{
C. DE LOORE and J.P. DE GREVE \\ Astrophysical Institute, VUB \\ Pleinlaan 2, B-1050 Brussels, Belgium
}

We calculated the evolution of both components of a massive binary system with masses $26 \mathrm{M}_{\mathrm{O}}$ and $23.4 \mathrm{M}_{\mathrm{O}}$, initial period 27.4 days, through a case $\mathrm{B}$ of mass transfer, up to the end of the core helium burning phase of the primary (and further to the end of the main sequence of the secondary). For the

WC phase we adopted Langer's (1989) mass dependent mass loss rate $\dot{\mathrm{M}}_{\sim} \mathrm{M}^{2.5}$ ). The luminosities were transformed to visual magnitudes, applying bolometric corrections for $\mathrm{O}$ stars of Code et al. (1976) and Flower (1977) and BC $=-4.5$ for the WR star (Smith and Maeder, 1989). If conservative mass transfer is adopted, the WR star is about 1.2 to 2.0 magnitude less brighter in the visual than the $\mathrm{O}$ star during the $\mathrm{WN}$ phase (lasting $1.510^{5} \mathrm{yr}$ ). The brightness difference reaches almost 3 magnitudes during the $\mathrm{WC}+\mathrm{O} 8$ phase (lasting $4.310^{5} \mathrm{yr}$ ), showing the system as a single-lined $\mathrm{O}$ type (!) spectroscopic binary. During the WR phase the mass function of this system varies from 0.67 $\sin ^{3}{ }_{i}$ to $0.05 \sin ^{3} i$ ! Nonconservative mass transfer and (or) a smaller initial mass ratio may result in the inverse situation, a single-lined WR binary with a large mass function (De Greve et al., 1988). Some of the results are shown in table 1 below.

Table 1 : Characteristics of the WR + O binary at the beginning of resp. the WN and the WC phase, and at the end of the WR phase (Mass loss in $10^{-5} \mathrm{M} / \mathrm{yr}$ ).

\begin{tabular}{ccrcccccc}
\hline & $\mathrm{t} / 106 \mathrm{yr}$ & $\mathrm{M}_{1}$ & $\mathrm{M}_{2}$ & $\log \mathrm{L}_{1} / \mathrm{L}_{\mathrm{O}}$ & $\log \mathrm{L}_{2} / \mathrm{L}_{\mathrm{O}}$ & $-\mathrm{M}_{\mathrm{v} 1}$ & $-\mathrm{M}_{\mathrm{V} 2}$ & $\dot{\mathrm{M}}_{\mathrm{WR}}$ \\
\hline $\mathrm{WN}_{\mathrm{i}}$ & 8.33 & 11.3 & 35.2 & 5.22 & 5.30 & 3.9 & 5.1 & 4.3 \\
$\mathrm{WC}_{\mathrm{i}}$ & 8.65 & 7.3 & 35.2 & 4.65 & 5.31 & 3.0 & 5.1 & 1.6 \\
$\mathrm{WR}_{\mathrm{f}}$ & 8.88 & 4.3 & 35.0 & 4.46 & 5.35 & 2.2 & 5.2 & 0.4 \\
\hline
\end{tabular}

\section{References}

De Greve, J.P., Hellings, P., van den Heuvel, E.P.J. : 1988, Astron. Astrophys. 189, 74

Code, A.D., Davis, J., Bless, R.C., Hanbury Brown, R. : 1976, Astrophys. J. 203, 417

Flower, P.J. : 1977, Astron. Astrophys. 54, 31

Langer, N. : 1989, Astron. Astrophys. 220, 135

Smith, L., Maeder, A. : 1989, Astron. Astrophys. 211, 71 